\title{
To the bottom of the heart: cloacal movement as an index of cardiac frequency, respiration and digestive evacuation in penguins
}

Received: 15 July 2003 / Accepted: 13 October 2003/Published online: 22 November 2003

(C) Springer-Verlag 2003

\begin{abstract}
A system is presented which uses a Hall sensor and an adjacent magnet, attached close to the cloaca of penguins, to record defecation, respiration and heart rates for both free-living birds and those in captivity. The output of the Hall sensor depends on a magnetic field, the strength of which is influenced in the presented scenario by the proximity of the magnet, which varies with movement of the cloaca. The elasticity of the cloaca results in minute, but perceptible, movements associated with the heart, respiration and defecation, although placement of the magnet and sensor is critical, and not all parameters can be measured all of the time. The system, incorporating a logger that can record at frequencies of $50 \mathrm{~Hz}$, was tested on 17 captive and 4 freeliving Magellanic penguins, Spheniscus magellanicus, in Argentina. It showed increased defecation rate associated with feeding, the expected trends in bradycardia
\end{abstract}

Communicated by O. Kinne, Oldendorf/Luhe

R. P. Wilson $(\bowtie) \cdot$ M. thor Straten $\cdot$ I. Zimmer $\cdot$ N. Liebsch A. Steinfurth · G. Müller

Institut für Meereskunde,

Düsternbrooker Weg 20,

24105 Kiel, Germany

E-mail: rwilson@ifm.uni-kiel.de

A. Scolaro · F. Quintana

Centro Patagonico,

Boulvarde Brown s/n, Puerto Madryn,

Chubut, Argentina

U. Siebert

Forschung und Technologie Zentrum,

Hafentörn, 25761 Büsum, Germany

K. Mills

PRBO Conservation Science,

Marine Ecology Division,

4990 Shoreline Highway,

Stinson Beach, CA 94970, USA

G. Spindler

Esmarchstrasse 75,

24118 Kiel, Germany and tachycardia associated with diving, and appeared to record some movement of air sacs associated with breathing. The concept of measuring minute changes in relative exterior body positions as a cue to internal processes may be important in future studies for both free-living and captive animals, particularly since it is non-invasive and relatively easy to deploy.

\section{Introduction}

Measurement of energy use, conservation and flow in ecosystems is paramount for understanding trophic function (Elton 1924). Not surprisingly, there have been numerous attempts to examine various aspects of energetics, especially energy management by individuals within a specific species. Of the many different methodological options used to study energetics, three of the most important approaches are: (1) measurement of rates of oxygen usage by examination of gas flow rates (e.g. Culik et al. 1994), (2) measurement of heart beat frequency (hereafter referred to as heart rate) as a proxy for energy expenditure (e.g. Butler 1993, and references therein) and (3) measurement of the rate of ingestion of foodstuffs (see e.g. Coates and Penning 2000, and references therein). This information is then combined with knowledge of assimilation efficiencies (e.g. Jackson 1992; Lawson et al. 1997; Rosen and Trites 2000) and defecation rates (e.g. Krysl et al. 1988) to derive the overall energy requirements (e.g. Winship and Trites 2002).

Most studies of this type concern animals in captivity (e.g. Culik et al. 1994), although careful electrode placement (Storch et al. 1999; Weimerskirch et al. 2000) or appropriate implantation techniques (e.g. Green et al. 2003) can also help to obtain heart rates for wild animals (e.g. Weimerskirch et al. 2002). Aside from straight observation, feeding rates of wild animals can be determined by a number of means, such as changes in stomach temperature (Wilson et al. 1992; Gales and Renouf 1993) or oesophageal temperature (Ancel et al. 
1997; Charrassin et al. 2001), particularly by the use of jaw sensors (e.g. Coates and Penning 2000; Plötz et al. 2001; Wilson et al. 2002a).

In the current paper we present results from preliminary trials on the use of a new sensory system, which we attached to measure cloacal activity of both freeliving and captive penguins. The system was based on the Hall effect (Hall 1879) and designed to measure distance or orientation changes between a sensor and a magnet placed on moving body parts, as is sometimes used in biomedical research (e.g. Cobern et al. 1983; Cholewicki et al. 1997). The extreme sensitivity of the system to minute movements meant that defecation, respiration and heart rates could be determined for at least some of the time that the animals were equipped. The versatility of the system means that it has the potential to elucidate processes of energy flux as well as energy expenditure, and thus it may be a particularly useful addition to the range of techniques already employed in this important area of research.

\section{Materials and methods}

\section{Initial calibration procedures}

The system to measure cloacal movement (the sensitive hind-part impulse measurement and storage unit; SHIMASU, Driesen and Kern, Bad Bramsted, Germany) was constructed of a small rare earth magnet and a Hall sensor linked via a thin cable to a logger. Nominally, the magnet was placed on one side of the cloaca and the Hall sensor on the other. The Hall sensor measures magnetic-field strength, producing output that is stored at frequencies defined by the user (typically 10-20 Hz); the perceived magnetic-field strength is dependent on the distance and angle between the sensor and the magnet. Both the Hall sensor and magnet have active faces so that, for example, only one face of the Hall sensor was sensitive to the south pole of the magnet; thus, care must be taken when the two components are set up (see following subsection). The logger was powered by a $3.6 \mathrm{~V}$ lithium battery and had a flash RA memory of $4 \mathrm{Mb})$. The electronics of the logger was cast in resin, the battery being contained within an associated turned-titanium housing. The electronics of the logger together with the battery housing had maximum dimensions of $75 \times 35 \times 20 \mathrm{~mm}$. The mass was $34 \mathrm{~g}$. The Hall sensor, also potted in resin (with dimensions of $2 \times 2 \times 1 \mathrm{~mm}$ ), was linked to the logger by a 0.8 -mm-diameter (ca. 100-mm-long), teflon-coated, six-strand cable, four of these strands being used for the sensor and two being redundant.

Neodinium boron rare earth magnets of various sizes were placed on a specially constructed rotatable rail system so that individual magnets could be moved to within precise distances of a Hall sensor (Siemens KSY 10). In addition, the active face of the magnets could be rotated to be at a precise angle with regard to the active face of the Hall sensor, this as a function of distance between the two elements. The response of the Hall sensor was then noted as a function of magnet dimensions, particularly the area of the active face.

\section{Captive penguins}

Between 13 August and 26 September 2002, two Humboldt penguins, Spheniscus humboldti, housed at Hagenbeck's Zoo, Hamburg, Germany, were each kept in open, wire-mesh, circular enclosures, with diameters of $140 \mathrm{~cm}$ (height $90 \mathrm{~cm}$ ) and a polythene base. The birds were fed varying quantities of sprat (Sprattus sprattus, $25-280 \mathrm{~g} \mathrm{day}^{-1}$ ) in a single feeding event between 0900
Fig. 1 Schematic diagram of the configurations used to fix the Hall sensor and magnet to penguin cloacas. The left hand column shows the actual configurations including peripheral elements: in versions 1 and 2 both magnet and Hall sensor are stuck directly to the feathers around the cloaca, in $2 a$ they are embedded in a plastic half-moon system, in $2 b$ they are embedded in a neoprene ring, in 3 they are stuck directly onto the cloaca itself and in 4 they are stuck on the feathers as in 1 and 2, but both the magnet and the Hall sensor have a different form (see "Materials and methods"). The second and third columns show the orientation of the active faces of the magnet (shown by the shaded area, the darker areas indicating increased magnetic field strength as a function of angle) and of the Hall sensor (the active face being stippled) during the normal cloaca position and during defecation. The fourth and fifth columns show the outputs recorded by the system, the fourth column being the expected output (conceived before the configurations were tested) and the fifth column being the observed output. The different degrees of cloacal opening and the consequences that this has on the measurement are shown for configuration $2 \mathrm{a}$

and 0930 hours. Subsequently, the exact time of all defecation events was noted, and the droppings were collected in a syringe and/or on a trowel and in pre-weighed tissue. The wet mass and dry mass of all samples were noted to the nearest $0.01 \mathrm{~g}$ on a Sartorius balance. This procedure was carried out for a total of 33 days.

Field work on both temporarily captive and free-living Magellanic penguins, Spheniscus magellanicus, was conducted at two sites in Argentina: Cabo Virgenes ( $\left.52^{\circ} 24^{\prime} \mathrm{S} ; 6^{\circ} 26^{\prime} \mathrm{W}\right)$, Santa Cruz, and San Lorenzo $\left(42^{\circ} 04^{\prime} \mathrm{S}\right.$; $\left.63^{\circ} 21^{\prime} \mathrm{W}\right)$, Chubut, between December 2001 and February 2003. Birds were equipped with SHIMASUs by having the rare earth magnet glued on one side of a penguin's cloaca and the Hall sensor to the other (Fig. 1; see below). In all cases where the SHIMASU was attached to penguins, the logger was placed on the mid-line of the penguins' lower backs (see recommendations in Bannasch et al. 1994), being held in place by overlapping strips of waterproof tape (see Wilson et al. 1997). The work on the penguins had two major phases: (1) determination of the best placement of the Hall sensor and magnet to provide a reliable recording of defecation, breathing and heart rates on captive birds and (2) deployment of the chosen system on freeliving penguins.

A total of 17 birds was chosen for the work in captivity, these birds being selected at the colonies to be, as far as could be ascertained, birds that were failed breeders. This was surmised after surveying prospective birds for a time to ensure that their behaviour was typical of non-breeding animals. Birds were chosen, for example, because they were associated with empty nests. In all cases of birds being equipped, the complete process took $<10 \mathrm{~min}$ and was primarily determined by the time it took the glue to hold the Hall sensor and magnet to the area around the cloaca. Examination of penguin defecation appeared to show that the cloaca everted during this process, so a number of magnet/Hall sensor configurations were attempted, to allow the relative positions of the two components to move so that the signal from the Hall sensor was optimised for the process of defecation (Table 1); the configurations shown in Fig. 1 are described below:

1. The active faces of both the magnet and the Hall sensor were stuck so as to lie face down on the feathers around the cloaca and parallel to the skin.

2. The magnet and Hall sensors were stuck on the feathers around the cloaca, with the active faces lying parallel and facing each other across the cloaca.

2a. Both the magnets and the Hall sensors were stuck as in configuration 2, but were embedded in plastic cut outs $(2 \mathrm{~mm}$ thick) in the shape of half-moons. The half-moons afforded stability in having a greater surface area to stick to the feathers around the cloaca. In addition, the magnets and sensors did not have their active faces quite parallel, being set so that the angle between the two faces decreased with increasing distance from the bird. 
(1)

\section{Configuration}

(2)

(2a)

(2b)

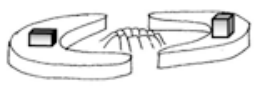

(3)

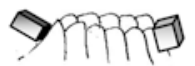

(4)

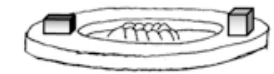

As in $(2 a)$
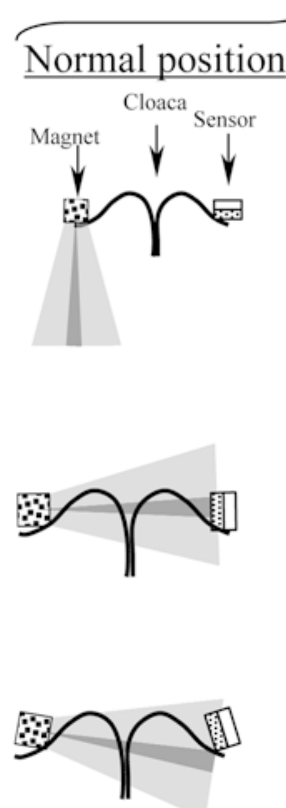

Cross-section

\%<smiles>CC1CCCCC12CCCC2</smiles>
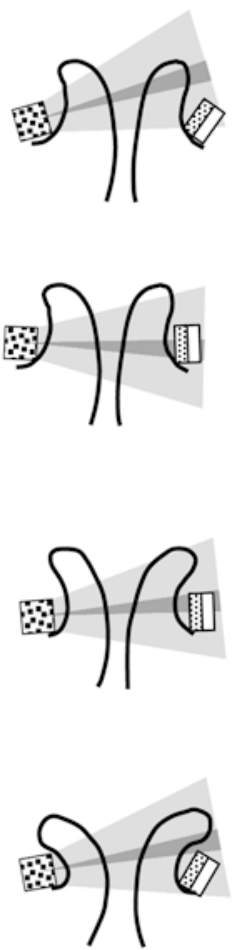

As in (2a)

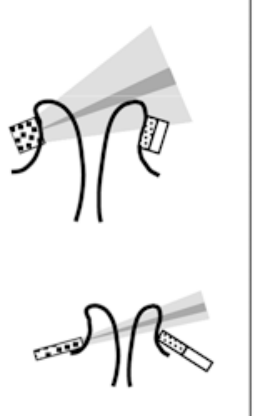

SHIMASU output

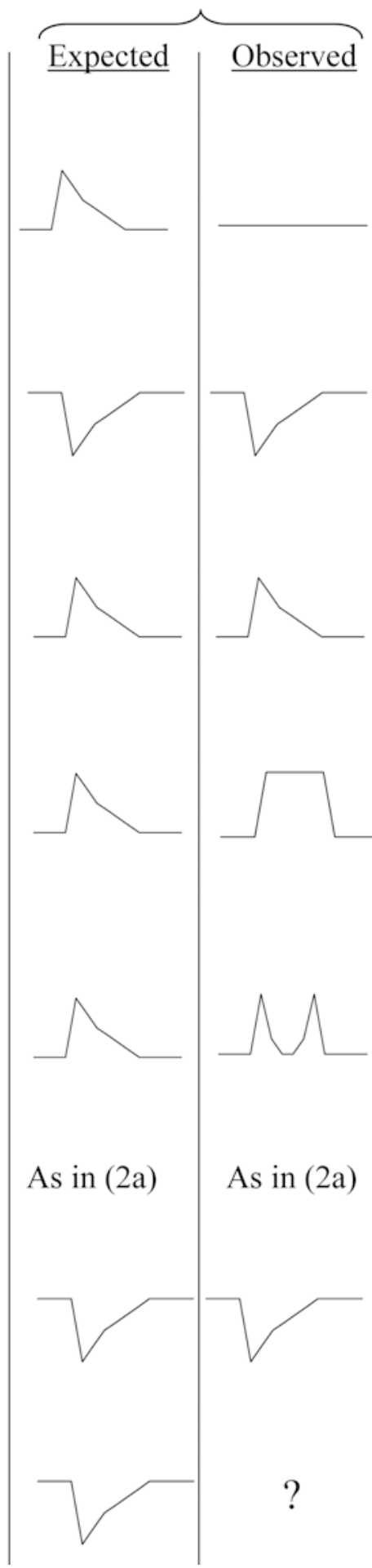

2b. As in configuration 2a, except that the magnet and Hall sensor were embedded in a neoprene ring ( $3 \mathrm{~mm}$ thick).

3. The Hall sensor and magnet were glued directly onto the cloaca, with the active faces approximately facing each other.

Two glue types were used: Poxypol (Industria Argentina), a quick-setting, two-component epoxy and cyanoacrylate (Uhu super glue, Germany), the former being used to stick the sensors and magnets onto the feathers around the cloaca and the latter being used to stick them directly onto the skin. After tests with the SHIMASU were completed, the elements stuck with glue were removed by sliding a finger nail between the magnet or sensor and the glue. The epoxy glue left a thin layer of glue still stuck to the feathers in the area around the cloaca, which would be lost at the latest during moult (normally 2-3 months later; see Williams 1995). The cyanoacrylate glue left a thin film either on 
Table 1 Spheniscus magellanicus. Deployments of SHIMASU on Magellanic penguins in Argentina, December 2001-February 2003

\begin{tabular}{|c|c|c|c|c|c|c|}
\hline ird & $\begin{array}{l}\text { Configu- } \\
\text { ration }\end{array}$ & $\begin{array}{l}\text { Recording Magnet } \\
\text { frequency size }(\mathrm{mm}) \\
(\mathrm{Hz})\end{array}$ & Site & $\begin{array}{l}\text { Duration } \\
(\mathrm{min})\end{array}$ & $\begin{array}{l}\text { Recorded } \\
\text { defecation }\end{array}$ & $\begin{array}{l}\text { Percentage Recorded Recorded Remarks } \\
\text { defecation breathing heart rate }\end{array}$ \\
\hline
\end{tabular}

\begin{tabular}{|c|c|c|c|c|c|c|c|c|c|c|}
\hline 1b1 & 1 & 16 & $8 \times 8 \times 6$ & Captivity & 400 & 0 of 7 events & 0 & No & No & Highly insensitive \\
\hline 4b3 & 1 & 16 & $8 \times 8 \times 6$ & Captivity & 180 & 0 of 2 events & 0 & No & No & Highly insensitive \\
\hline bt25 & 1 & 16 & $8 \times 8 \times 6$ & Captivity & 350 & None $^{\mathrm{a}}$ & - & No & No & Highly insensitive \\
\hline $\operatorname{sh} 25-1$ & 1 & 16 & $8 \times 8 \times 6$ & Captivity & 20 & 0 of 1 event & 0 & No & No & Highly insensitive \\
\hline b2-1 & 1 & 20 & $8 \times 8 \times 6$ & Captivity & 60 & 1 of 9 events & 11 & No & No & Highly insensitive \\
\hline b1-1 & 1 & 20 & $8 \times 8 \times 6$ & Captivity & 40 & 1 of 7 events & 14 & No & No & Highly insensitive \\
\hline $2 \mathrm{~b} 4$ & 2 & 16 & $8 \times 8 \times 6$ & Captivity & 390 & 1 of 5 events & 20 & No & No & $\begin{array}{l}\text { Non-definitive } \\
\text { defecation pattern; } \\
\text { sensor noise during } \\
\text { movement }\end{array}$ \\
\hline $3 \mathrm{~b} 2$ & 2 & 16 & $8 \times 8 \times 6$ & Captivity & 370 & 1 of 4 events & 25 & No & No & $\begin{array}{l}\text { Non-definitive } \\
\text { defecation pattern; } \\
\text { sensor noise during } \\
\text { movement }\end{array}$ \\
\hline bot24-2 & $2 \mathrm{a}$ & 20 & $8 \times 8 \times 6$ & Captivity & 40 & 7 of 7 events & 100 & $?$ & Yes & $\begin{array}{l}\text { Heart rate sometimes } \\
\text { around defecation }\end{array}$ \\
\hline bd49-3 & $2 b$ & 20 & $8 \times 8 \times 6$ & Captivity & 130 & 7 of 14 events & 50 & Likely & Yes & $\begin{array}{l}\text { Neoprene sagged, } \\
\text { reducing sensitivity } \\
\text { over time }\end{array}$ \\
\hline $\mathrm{S} 1$ & $2 b$ & 10 & $8 \times 8 \times 6$ & Captivity & 100 & $>4$ of 13 events & $>31$ & & & $\begin{array}{l}\text { Device incompletely } \\
\text { read out; data access } \\
\text { problems }\end{array}$ \\
\hline S3 & 3 & 10 & $6 \times 2 \times 2$ & Captivity & 60 & $>2$ of 11 events & $>18$ & $?$ & $?$ & $\begin{array}{l}\text { Magnet dislodged } \\
\text { during trial }\end{array}$ \\
\hline $\mathrm{S} 2$ & 3 & 10 & $6 \times 2 \times 2$ & Captivity & 20 & $>1$ of 7 events & $>14$ & $?$ & $?$ & $\begin{array}{l}\text { Magnet dislodged } \\
\text { during trial }\end{array}$ \\
\hline Xing & $2 b$ & 10 & $8 \times 8 \times 6$ & Free-living & 2520 & Yes & - & Yes & Yes & $\begin{array}{l}\text { Periods of minimum, } \\
\text { constant values } \\
\text { (see text) }\end{array}$ \\
\hline
\end{tabular}

${ }^{\mathrm{a}}$ Defecation events not counted

the feathers or on the skin, which we consider would have been lost within a few days. Had the cyanoacrylate glue bonding to the cloaca skin been so strong that there was a risk of damaging the skin when the sensory system was removed, we would have simply cut the cable and left both magnet and sensor in place until they fell off.

The penguins equipped with the SHIMASU in captivity were kept in various wire cages or compounds (dimensions varying between $5 \times 5 \mathrm{~m}$ and $1 \times 1 \mathrm{~m}$ ) in the colony for maximum periods of up to $7 \mathrm{~h}$, after which the units were removed and the birds released in the colonies at the sites they were found. During the time in captivity the birds were watched continuously and the exact time of any defecation noted as well as other behaviour that might be relevant, such as preening near the tail. Three equipped birds were also kept in cages with plastic substrate, and all faeces were collected and weighed immediately.
Free-living penguins

Four free-living Magellanic penguins brooding chicks were also equipped with devices. Each device contained two Hall sensors, leading to the single loggers which stored the data in two channels. The two sensors were essentially identical, except that the one Hall sensor/magnet combination was used on the cloaca and another on the beak so as to measure breathing and feeding behaviour (Wilson et al. 2002a, 2003). Here, the birds were removed from nests using the clip-board technique described in Wilson et al. (2002b), equipped and then replaced back on the nest. The equipment procedure for the SHIMASU was nominally the same as that used for the caged birds, except that care was taken to hide the cable running between the sensor and the logger. For this, the cable was led under the feathers and held in place by using drops of the cyanoacrylate glue to hold feather pairs together with the cable 
running between them. The sensory system used to monitor beak movement was stuck in place using Poxypol glue (for details see Wilson et al. 2002a). Nests with equipped birds were observed whenever possible, but were, in any event, surveyed four times per day until the equipped penguins had gone to sea for a single foraging trip. The devices were removed when the birds returned, and the data were transferred to computer via a two-pin interface.

Downloaded data were converted from binary to ASCII format using the software INFRALOG (Driesen and Kern) and then visualised by the program MT-beak (Jensen Software Systems, Laboe, Germany). This program allows extensive serial datasets with a common time base to be graphed above each other for inspection. The complete dataset, or sections of it, can be visualised according to user specifications and examined for concurrence between changes in sensor output and bird activity. Nominally, the devices logging Hall sensor outputs showed values of between 0 and $2500 \mathrm{mV}$. MT-beak was set so as to identify sudden changes in millivolt values that might correspond to defecation events. Both identified changes and those identified by the user as relevant (according to written protocols of bird activity) were examined.

\section{Results}

Initial laboratory calibrations

There was an obvious, exponential-type decay response of the Hall sensor to the magnet as a function of distance between the magnet and the sensor (Fig. 2), the response being most dramatic for magnets with the largest volume. This response was, however, modified by the angle between the active face of the Hall sensor and the active face of the magnet, varying as a function of the surface area of the active magnet face. Variation in angle between magnet active face and sensor active face for any given distance produced a smaller response in sensor output for magnets with larger active-face surface areas (Fig. 2).

\section{Captive birds}

Mean rates of defecation for wild Magellanic penguins (Spheniscus magellanicus) temporarily placed in captivity were once every $17 \mathrm{~min}$, although there was considerable variation, with rates varying between once every 2.8 and once every $90 \mathrm{~min}$ (cf. Table 1), presumably as a function of stress and the digestive states of the birds. Where the wet mass of the guano was measured after each defecation event, mass was found to be related to the time between events (Fig. 3a; $F=8.0>4.35, P<0.05$ ). Although this relationship is significant, the rate of guano production over time is likely to be more complicated than the simple linear relationship implied, because guano can only be produced when the digestive system has food with which to work. The two Humboldt penguins (Spheniscus humboldti) in the zoo, which, despite massive variance, produced faeces with a mean wet mass of $0.95 \mathrm{~g}(\mathrm{SD}=0.71, N=430)$ after a mean of $18.5 \mathrm{~min}(\mathrm{SD}=19.3)$, also showed a significant relationship between the wet mass of guano measured after each defecation event and the inter-event duration
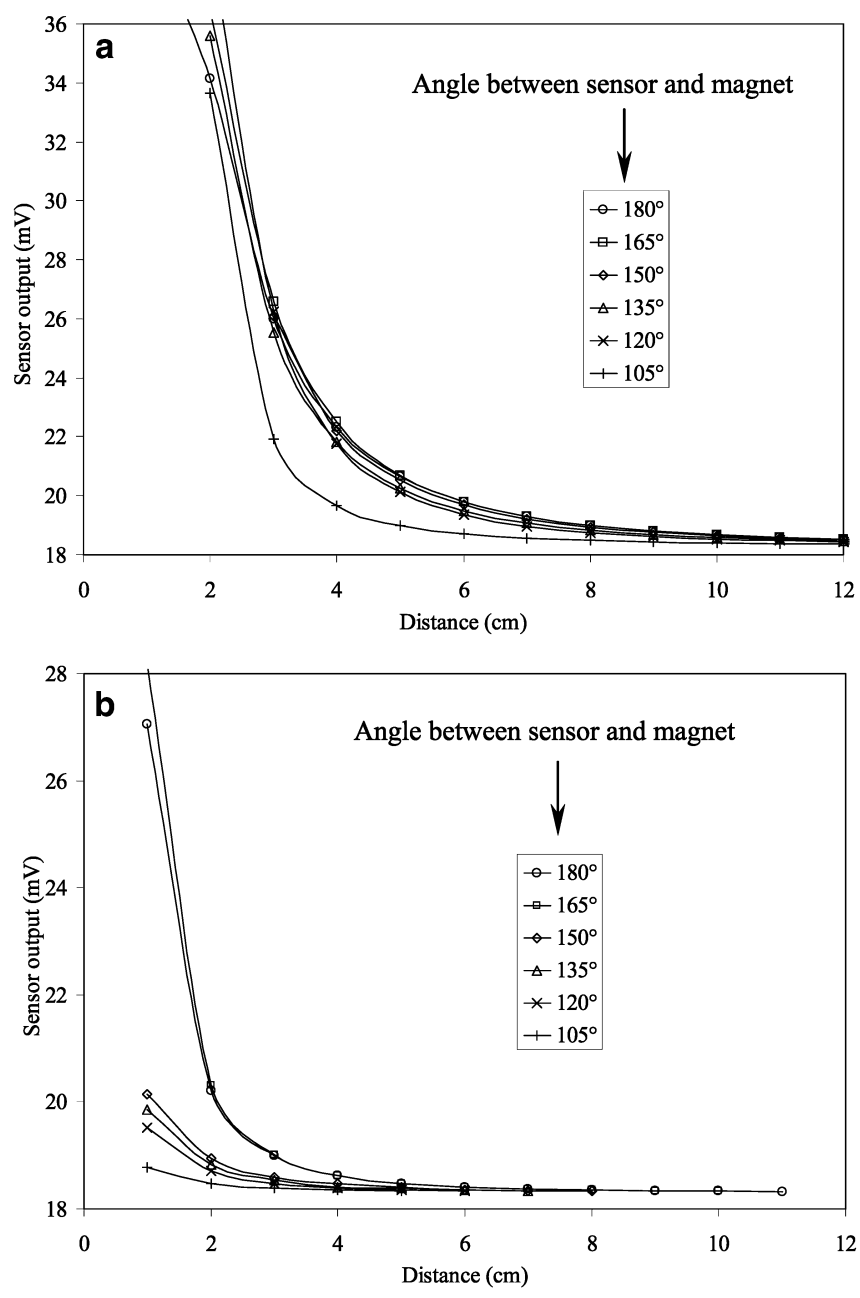

Fig. 2 Relationship between Hall sensor output, distance between sensor and magnet and angle of the active faces of the sensor and magnet for: a a magnet with a large surface area (diameter $34 \mathrm{~mm}$ ) for its active face and $\mathbf{b}$ a magnet with a small surface area for its active face (diameter $9 \mathrm{~mm}$ ). The values shown as insets refer to the angles used, whereby $180^{\circ}$ indicates that the two active faces were parallel and $90^{\circ}$ would have been perpendicular

(Fig. 3b; $F=8.71>6.69, P<0.01$ ), although the rate of guano evacuation was dependent on the maximum period over which this regression was set to apply; this became apparent if the regression was run a number of times with varying maximum $x$-values allowed. If the gradients of these latter regressions (forced to bisect the $x=0$ and $y=0$ point) were themselves regressed against the respective maximum durations allowed in the regressions, the relationship showed an exponential decay-type curve, with highest rates of evacuation occurring over the shortest intervals (inset in Fig. 3b). Rates of evacuation determined by these means were generally higher than values derived by simply dividing the mean evacuation mass for any particular inter-evacuation interval by the value of that interval (inset in Fig. 3b).

The output of the sensors was highly dependent on the configuration adopted for the sensory set-up of the SHIMASU (Fig. 4). Configuration 1 recorded only 2 


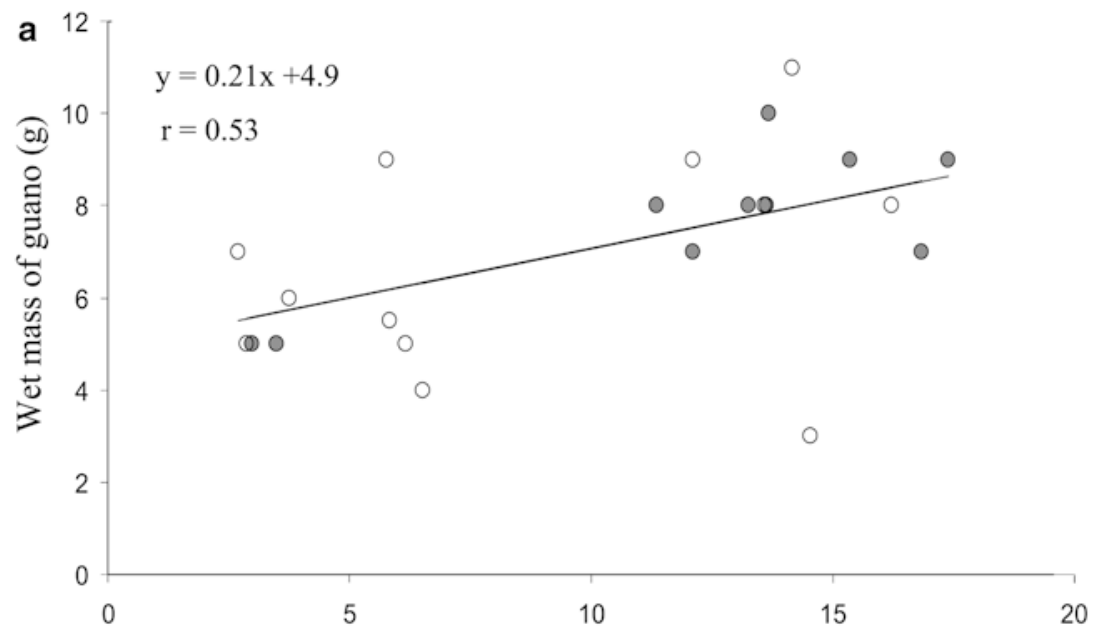

Time between defaecation events ( $\mathrm{min})$

b
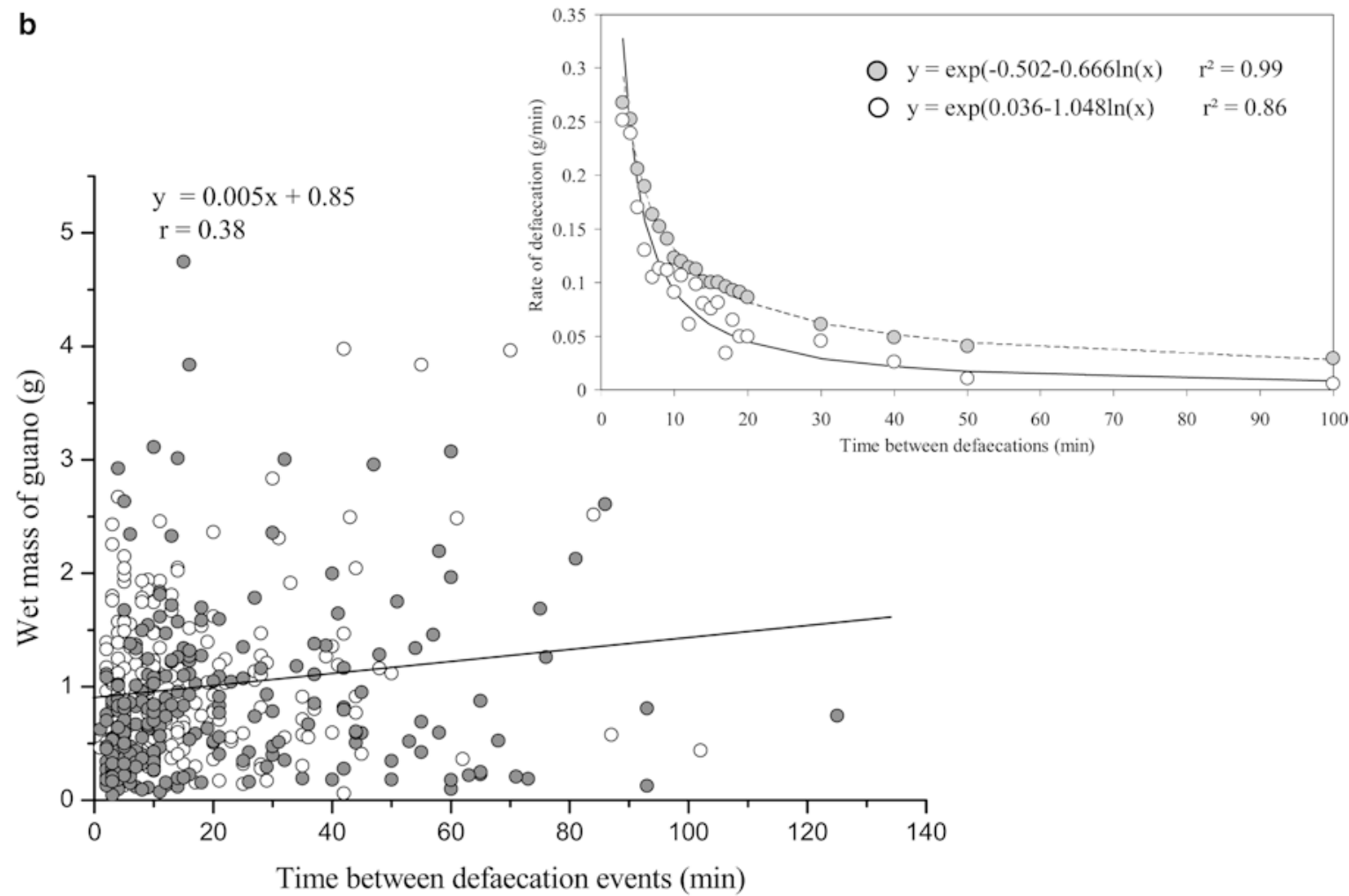

Time between defaecation events (min)

Fig. 3 Spheniscus magellanicus, S. humboldti. Relationship between the wet mass of guano evacuated per defecation event and the time between defecation events for: a two (filled and open circles) wild Magellanic penguins temporarily held in captivity and $\mathbf{b}$ two (filled and open circles) Humboldt penguins bred and held in captivity. The inset shows two measures of effective rate of defecation with appropriate curve fits to those data for both birds combined; filled circles show the gradients of the graph of guano mass voided versus time between defecation events for data from time 0 to time $N, N$ being given by the $x$-axis. Open circles show the rate of defecation as given by the mass of guano voided after any specific inter-void minute interval ( $x$-axis) divided by that interval

defecation events $(7 \%)$ of a total of 30 events from seven different birds. Configuration 2 recorded 2 $(22 \%)$ of 9 events from two birds, while configura- tion $2 \mathrm{a}$ recorded $18(100 \%)$ of 18 events from three penguins. Configuration 2c initially recorded all events, but became poorer over time as the neoprene became wet and sagged, reducing sensitivity; so that overall (and if bird S1 is ignored; see Table 1) a total of 19 $(58 \%)$ of 33 events was recorded. The actual signals produced by SHIMASUs with configurations 2a and $2 \mathrm{~b}$ conformed to a standard pattern, which took three basic forms (Fig. 4). In all of these forms, the output value initially decreased for a mean period of $2.2 \mathrm{~s}$ $[\mathrm{SD}=2.2, N=27$ (the first half of the values from birds bd24-3 and bd49-3 are included in this analysis; Table 1)], before increasing rapidly within $1 \mathrm{~s}$ (Fig. 4). 
Fig. 4a-c Spheniscus magellanicus. Variability in the output signal of the SHIMASU during defecation events (indicated by arrows) compared to the rate of change of the sensor output for the same periods. The three major patterns $(\mathbf{a}-\mathbf{c})$ derived from sensor fittings corresponding to configurations $2 \mathrm{a}$ and $2 \mathrm{~b}$ are shown (see "Results")
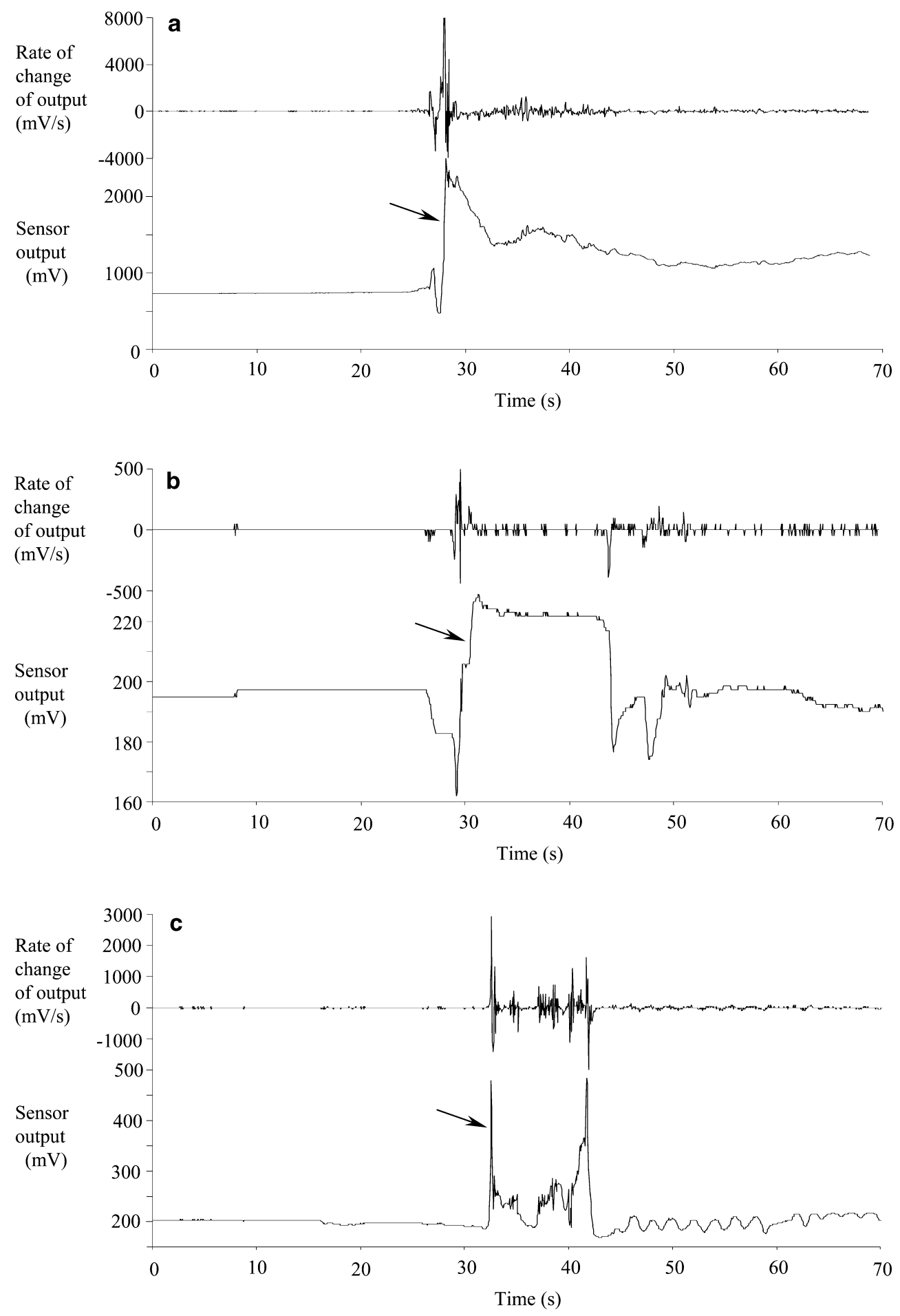

During the increase phase there was a high, distinctive rate of change of sensor output (Fig. 4), which was immediately followed by the emergence of the faeces. Subsequently, sensor values followed one of three patterns, indicating the effective closure of the cloaca to terminate the defecation event: (1) most output values $(74 \%)$ slowly decreased over time to reach levels approaching pre-event values (Fig. 4a), (2) some values $(18 \%)$ remained high for a period before dropping, giving a square-wave pattern to the trace over time before dropping again (Fig. 4b) and (3) occasionally $(8 \%)$ values decreased for a while prior to increasing again before finally decreasing to pre-event levels (Fig. 4c). The mean time taken for the sensor output to return to baseline levels after the initial increase was $6.6 \mathrm{~s}(\mathrm{SD}=3.8, N=27)$.

There was little variation in sensor output from any penguin activity for configuration 1 . Other configura- 
Fig. 5a-e Spheniscus magellanicus. Data derived from a SHIMASU used on a free-living Magellanic penguin at sea to show some of the major features. The bars in each diagram denote periods at the sea surface. a Three consecutive dives and $\mathbf{b}$ a single dive during which the sensor and magnet moved so far apart that no resolution was possible, rendering the system useless at this time. Note: the inset, which covers a period of $7 \mathrm{~s}$, shows how the single, stable, minimum value changes so that the system can record variability again as the bird adjusts its tail angle in preparation for the return to the surface. c A single dive during which a penguin defecated (arrow) (cf. Fig. 4). A section of the dive comparable to that shown in panel $b$ has been enlarged to show how the output should look when the magnet and sensor are appropriately placed. d, e Dives in which the form of the dive profile (depth over time) can be inferred by examining changes in penguin tail position. The dives are considered to take the form of: $\mathbf{d}$ a dive with two major undulations and $\mathbf{e}$ a dive with three major undulations (see Simeone and Wilson 2003 for a discussion of this). For comparison, panel c shows a simple "parabolic" dive (cf. Wilson et al. 1995) with no undulations
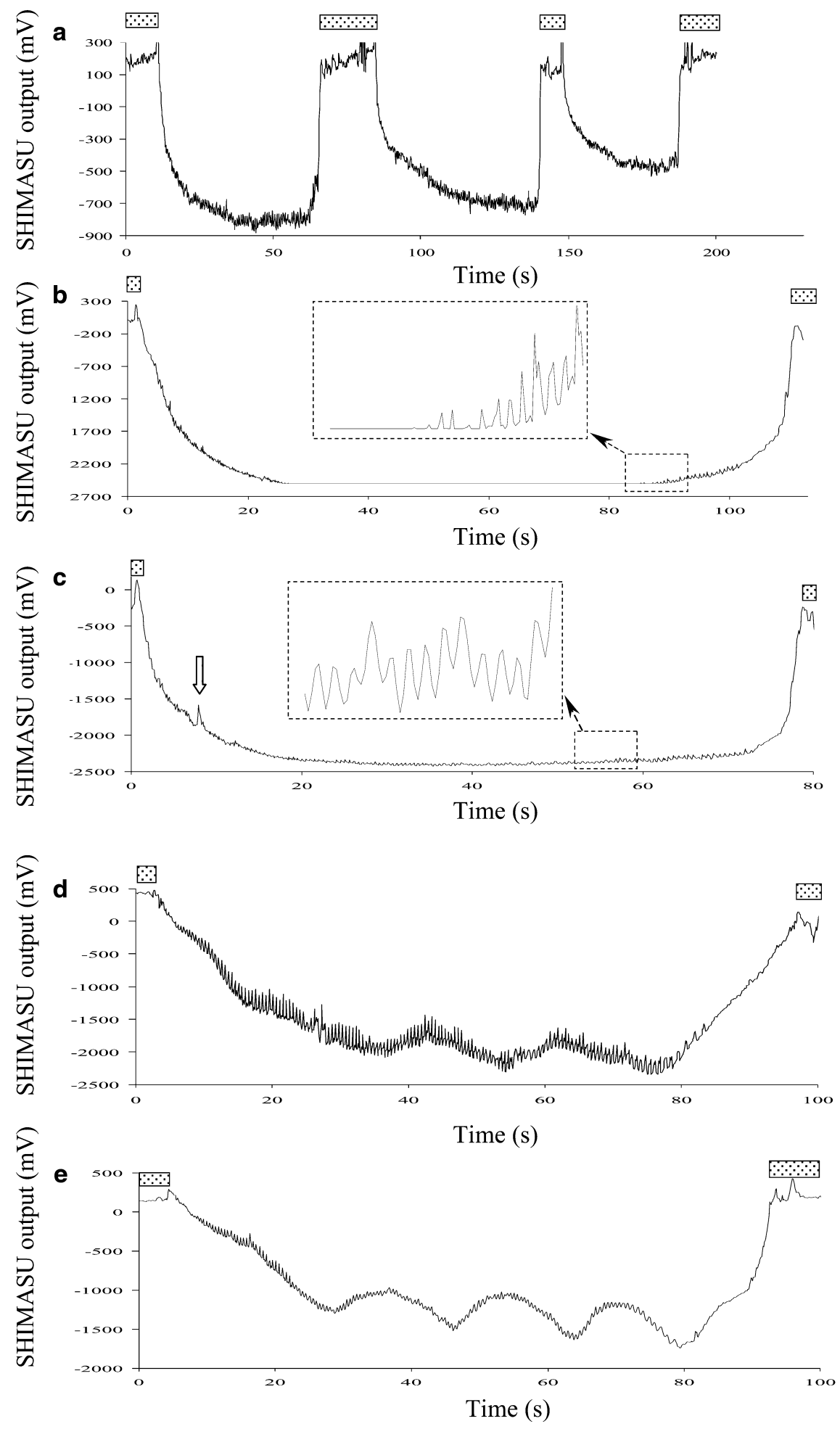

tions, however, showed some change in sensor output with penguin movement, this being particularly obvious for configuration 3 , where the "moment arm" effect of the cable attached to the small sensor attached directly to the cloaca meant that small changes in the position of the cable leading to the cloaca led to massive changes in angle between sensor and magnet. Cases where the systems were glued to give the flattest profile showed the least variation in sensor output in response to general activity other than defecation.

No penguins equipped with SHIMASUs using configurations 1 or 2 showed patterns that could be interpreted as due to breathing or heart rate. However, three of the three birds equipped according to configuration $2 \mathrm{a}$ and two of the three equipped with configuration $2 \mathrm{~b}$ showed patterns indicative of breathing (see the 


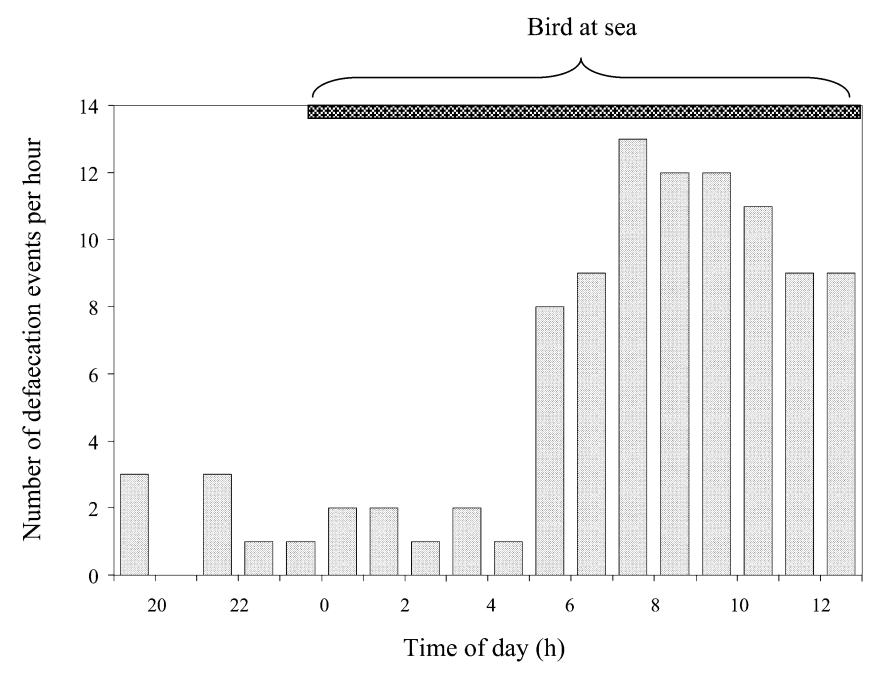

Fig. 6 Spheniscus magellanicus. Rate of defecation by one of the free-living Magellanic penguins as determined by a SHIMASU. Note: the bird went to sea around midnight, but there was no increase in the rate of defecation until around 0600 hours. Although the system on this bird logged for the full foraging trip, portions of the dives after 1300 hours were unusable due to the magnet and sensor moving too far apart (cf. Fig. 5b) so that counting had to be discontinued

following subsection), although we had no independent measure of this activity for these animals. Two of the three equipped according to configuration $2 \mathrm{a}$ and two of the three equipped according to configuration $2 \mathrm{~b}$ showed patterns that were indicative of heart rate (for a detailed discussion of this see the following subsection).

\section{Free-living birds}

Three of the four free-living penguins equipped with SHIMASUs (Table 1) logged data for the full duration of the foraging trips. Water entered the battery housing of a single bird, stopping recording after $4 \mathrm{~h}$ at sea. Diving activity, which was ascertained by the very characteristic patterns of breathing exhibited at this time (Wilson 2003; Wilson et al. 2003), was recorded by the units as a systematic drop in SHIMASU sensor output (Fig. 5a), although there were also periods when the system recorded continuous minimum values of $-2500 \mathrm{mV}$, presumably due to movement of the cloaca taking the magnet too far away from the sensor (Fig. 5b, cf. Fig. 5c). The characteristic drops in SHIMASU output voltage during dives were likely to have been due to the system recording penguin tail angle, since dives occasionally showed deviations in SHIMASU output voltages (Fig. 5d, e) that corresponded well to undulations in depth known to occur in Magellanic penguins during prey pursuit (Simeone and Wilson 2003). Defecation by the free-living penguins could be recorded well (Fig. 5c), mirroring that recorded for the birds in captivity. Occasional periods where the magnet moved too far away from the sensor (cf. Fig. 5b) made it impossible for us to assess defe- cation rates over the whole of the foraging trip for any of the free-living penguins. However, for the initial periods, where this error did not occur, the equipped birds showed substantial increases in defecation rates at particular points in the foraging trips (Fig. 6), presumably due to digestion of food eaten during that foraging trip.

SHIMASU output values were clearly related to breathing in penguins on land, as evidenced by the beak angle sensor (Fig. 7a). However, there were times when breathing was apparently recorded by the SHIMASU in penguins resting on land even though it was not discernible by the beak sensor (Fig. 7b). Generally, breathing was not apparent in birds at sea using the SHIMASU, either during extended periods at the sea surface, when respiration rates and tidal volumes (as determined via changes in beak angle over time; cf. Wilson et al. 2003) were low (Fig. 7c), or during the short inter-dive pauses occurring within diving bouts, when respiration rates and tidal volumes were high (Fig. 7d). Close examination of the SHIMASU values in relation to the breathing cycle showed infra-cyclic repeating patterns (Fig. 8).

Amplification of the SHIMASU output in a temporal sense showed that a regular wave pattern was apparent for much of the period that the birds were equipped (Fig. 9). This wave pattern, which we assumed to be heart rate due to the similarity in values between our study and that by Regel (1997) while working on Magellanic penguins at the same site, was particularly apparent during dives, becoming less obvious at the beginning and the end of the dive and for the inter-dive period at the surface (Fig. 9b), except for times when birds rested for extended periods (Fig. 7c). Overall, heart rate decreased over the course of the dive, rising only as the dive terminated (Fig. 9c), and minimum heart rates during the dives were negatively correlated with dive duration (Fig. 9d).

\section{Discussion}

The equipment of penguins with external devices has been shown to affect aspects of their foraging performance (e.g. Wilson et al. 1989; Taylor et al. 2001), and we consider that our units are likely to have affected the penguins in some way (Wilson and Culik 1992). Nonetheless, there were no obvious differences between equipped and unequipped birds, which leads us to believe that the device effects may not have been substantial and were unlikely to have affected the birds markedly over the short test period. This topic needs further work, however, particularly if animals are to be equipped over durations encompassing days or more.

The SHIMASU showed promise for measuring cloacal movement over a range of scales which proved useful for three major processes: defecation, breathing and heart rate. In addition, tail movements were also 
Fig. 7a-d Spheniscus magellanicus. Examples of the response of the SHIMASU to breathing by free-living Magellanic penguins. a Breathing cycles (of a penguin at rest on the nest), as apparent in the beak opening (Wilson et al. 2003) and as visible in the values recorded by the SHIMASU. b Breathing cycles (of a penguin at rest on the nest), although not apparent in the beak opening (note the difference in $y$-axes between panels a and $b$ ), are still visible in the SHIMASU values. c Breathing cycles of a penguin resting for extended periods at the sea surface, as apparent by changes in the beak angle (note: changes in beak angles are ca. 10 times greater than in panel a and that the inspiration rate is also about twice as high). Here, the SHIMASU was apparently incorrectly positioned to record breathing, but recorded heart rate well (see Fig. 9). d

Breathing cycles of a penguin resting briefly at the sea surface between dives during a diving bout, as apparent by changes in beak angle (note: changes in beak angle are ca. 10 times greater than those in panel c and 100 times greater than those in panel a). At this time the SHIMASU recorded neither breathing nor the heart rate (see Fig. 9)
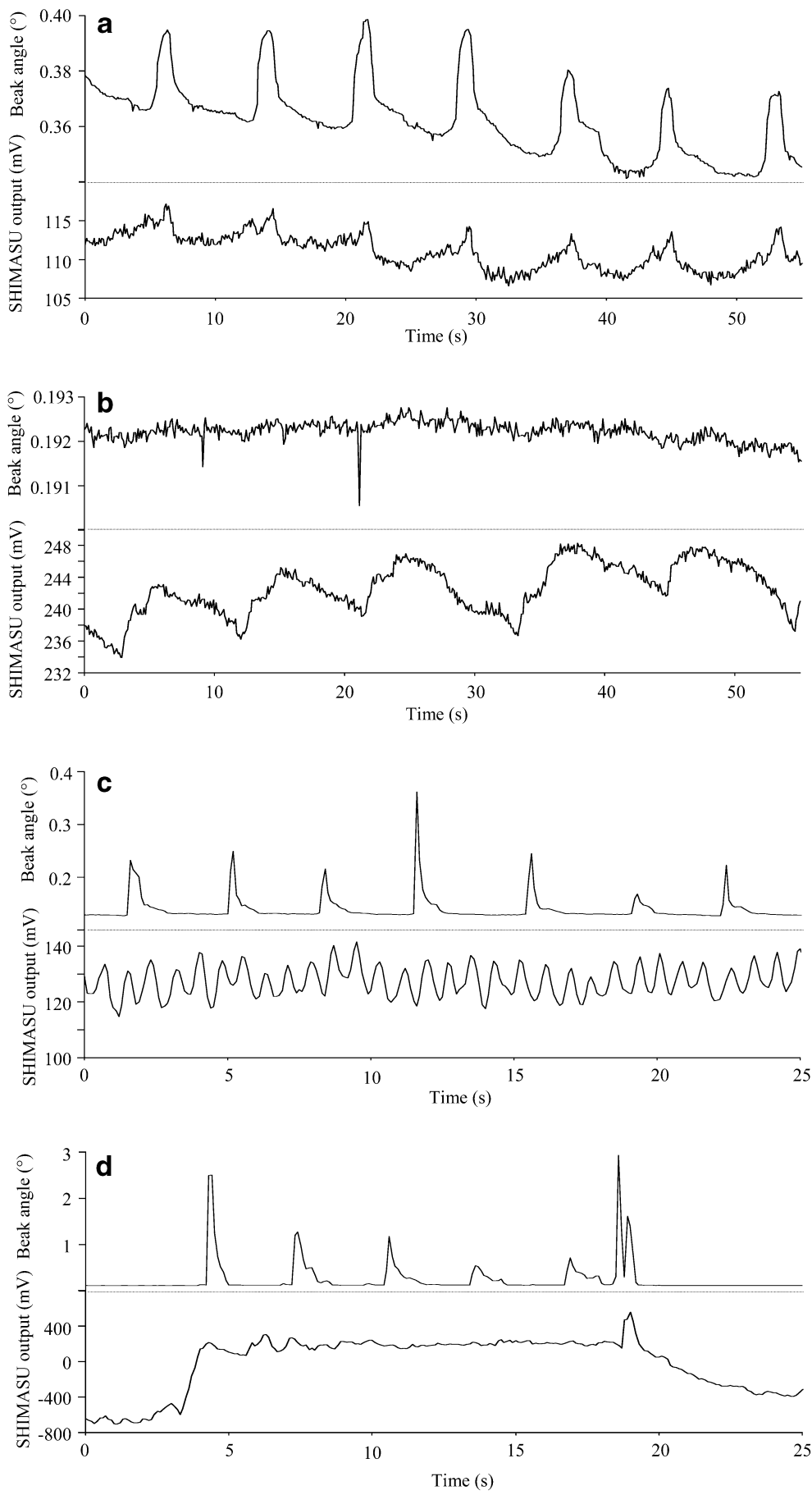

recorded by the methodology. It should be noted, however, that the system apparently does not work for all the processes all of the time, which would appear to limit its use. There are a number of reasons for this, most important of which appears to be the manner in which the sensor and magnet are applied. This is discussed in detail for the measurement of defecation below. With regard to the other parameters, such as breathing rhythms and heart rate, further work is needed, with more individuals and under carefully controlled conditions, in order to tease out the factors which are important when considering the extent to which the system can record the required information.

The ability of a single system to act over a number of quite different scales can be attributed to the exponential form of the relationship between Hall sensor output and the distance between sensor and magnet (Fig. 2) and the high (16 bit) resolution of the device. When the magnet is close to the sensor, minute changes in magnet-sensor distance produce a marked response in Hall sensor output (Fig. 2), which is presumably the feature that makes measurement of heart rate possible. Despite this, 

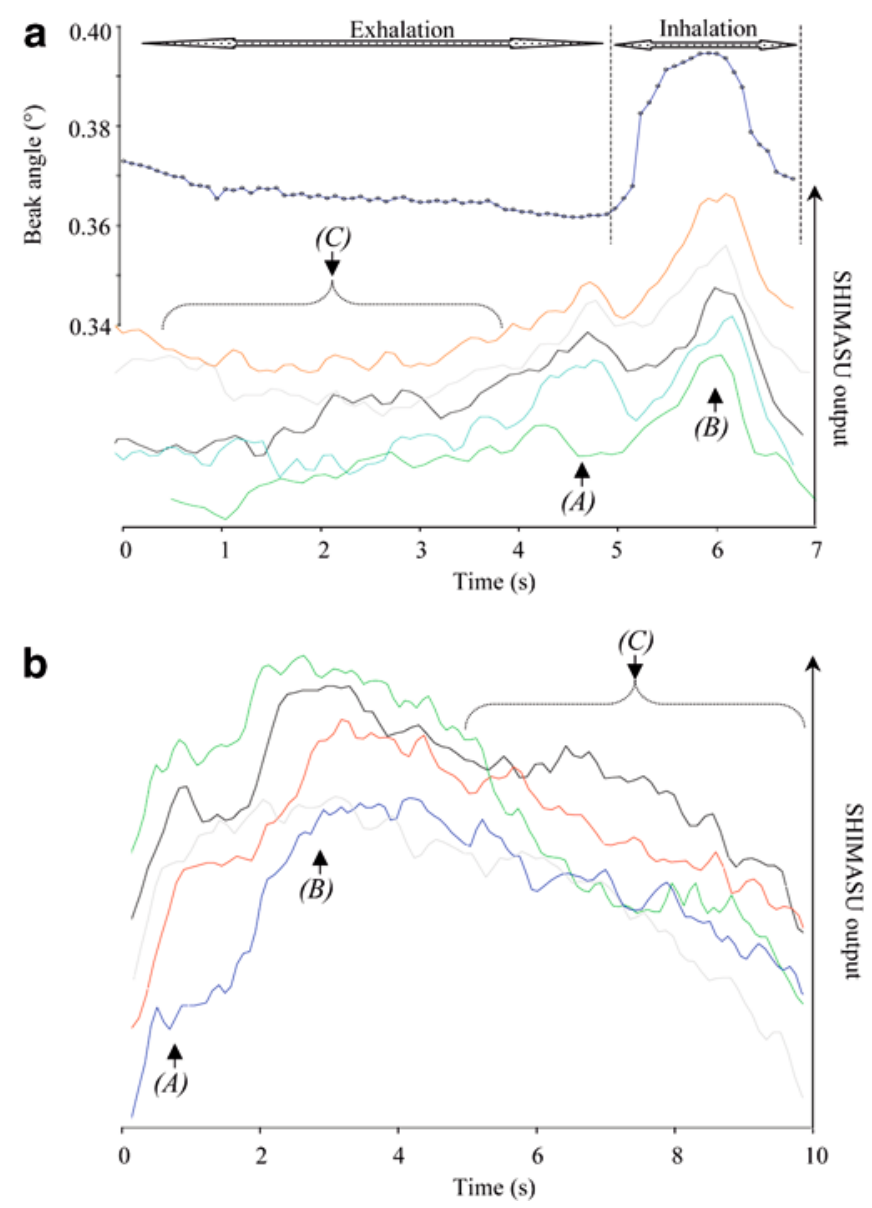

Fig. 8a, b Spheniscus magellanicus. Breathing cycles from Fig. 7 enlarged and superimposed to show general patterns in the recorded values. a A single (approximately representative) breath, as elucidated by changes in the beak angle as a point of reference for the SHIMASU values from Fig. 7a. b An illustration derived from values from Fig. 7b; there was no change in beak angle which could be used as a point of reference. In both panels a and b the time scale is only approximate and, due to the optimal superimposition of cycles, the SHIMASU output scale is not shown, but can be alluded to by consideration of Fig. 7. To partially eliminate noise due to heart rate (see Fig. 9) the data have been smoothed according to $X_{n}^{\prime}=X_{n-1} / 4+X_{n} / 2+X_{n+1} / 4$. Three major phases can be recognised: a small peak $(A)$ preceding a larger peak $(B)$, which occurs at the time of air inflow through the beak, followed by an extended period with a low rate of change of sensor output $(C)$

larger movements, such as those that occur during breathing (and here we speculate that inflation of the air sacs results in a general outward movement of the cloaca) and the comparatively massive movements that occur during defecation can also be recorded. It is notable here that in this application of a Hall sensor and magnet for detection of movement, no direct calibration is possible. This means that the recorded movement cannot be linearised as is possible in measurement of beak (Wilson et al. 2002a) or limb movement (Wilson and Liebsch 2003). This has consequences for determination of amounts defecated and air inhaled (see following subsections), but still allows events to be counted over time.

\section{Defaecation}

The results from this study make it clear that the manner in which the sensor/magnet system is positioned on the penguin is critical, as is the exact size and shape of the magnet. We were correct in surmising that the cloaca everts during defecation in penguins, but overestimated the extent of this eversion during preliminary trials using configuration 1 (Fig. 1). Clearly, the cloaca did not evert enough to bring the active face of the sensor to an appropriate angle to the magnet so as to induce a change in voltage (cf. Fig. 2). Configurations $2 \mathrm{a}$ and $2 \mathrm{~b}$ had the active surfaces of the magnet and sensor close to parallel, but in the normal resting position the active elements were slightly tilted with respect to each other in having the distance between the edges of the active surfaces immediately adjacent to the bird greater than the distances of the distant edges (Fig. 1). This configuration defines defecation events clearly (Fig. 4a), but can lead to plateaus in values as the magnet/sensor angle passes through the positions approximating parallel (Fig. 4b), or can even lead to temporary drops in sensor output if the degree of cloacal eversion is extreme enough (Fig. 4c). We note that the length of plateaus (Fig. 4b) is likely to be greater when the surface area of the active face of the magnet is larger (cf. Fig. 2).

The move towards parallel active faces during defecation for configurations $2 \mathrm{a}$ and $2 \mathrm{~b}$ produces an increase in sensor response (cf. Fig. 2), which is actually counteracted by the opening of the cloaca, which tends to move the active faces away from each other. Ideally, both the process of cloacal opening and the change in angle should produce reactions leading to a sensor response in the same direction. This can be achieved if workers set up systems so the active faces are parallel (at $180^{\circ}$ ) to each other, if possible, or so that the two active faces are placed so that the edges immediately adjacent to the penguin body tend to be closer than those distant. Cloacal movement during defecation would then decrease the angle (as the active faces of the Hall sensor and magnet moved away from being parallel), which would decrease sensor output. The increase in distance between magnet and sensor as the cloaca opened would have a similar effect. Thus, defecation would produce a consistent drop in sensor output, with no chance of either square waves (Fig. 4b) or "valley" patterns (Fig. 4c). In addition, to ensure that the system has maximum sensitivity, the magnet should have an active face with a small surface area, because trials with magnets under controlled conditions showed that Hall sensors were less sensitive to angle changes when the magnets had larger active surface areas (Fig. 2). Finally, the overall magnet and embedded Hall sensor shape should be flat (see configuration 4 in Fig. 1), so that it lies properly parallel to the body surface and projecting minimally from the surface, to reduce noise due to extraneous events.

Our analysis regarding the placement of the SHIMASU sensors indicated, post hoc, the best configura- 
Fig. 9a-d Spheniscus magellanicus. Examples of changes in heart rate during diving in a Magellanic penguin as elucidated by a SHIMASU. a SHIMASU output over a typical dive (indicated by the horizontal stippled bar; cf. Fig. 5) and b 5-s sections of the dive. c Heart rate over the course of the dive. For this, and to facilitate counting, the data (recorded at $10 \mathrm{~Hz}$ ) were smoothed according to $X_{n}^{\prime}=X_{n-1} / 4+X_{n} / 2+X_{n+1} / 4$. Question marks indicate periods in which the peaks and troughs were not easy to determine for some, or all, regions of the 5-s period. d Relationship between minimum heart rate during any particular dive and the duration of that dive for 50 dives made by a Magellanic penguin equipped with a SHIMASU $(F=43.2>12.3, P<0.001)(\mathrm{bpm}$ beats per minute)
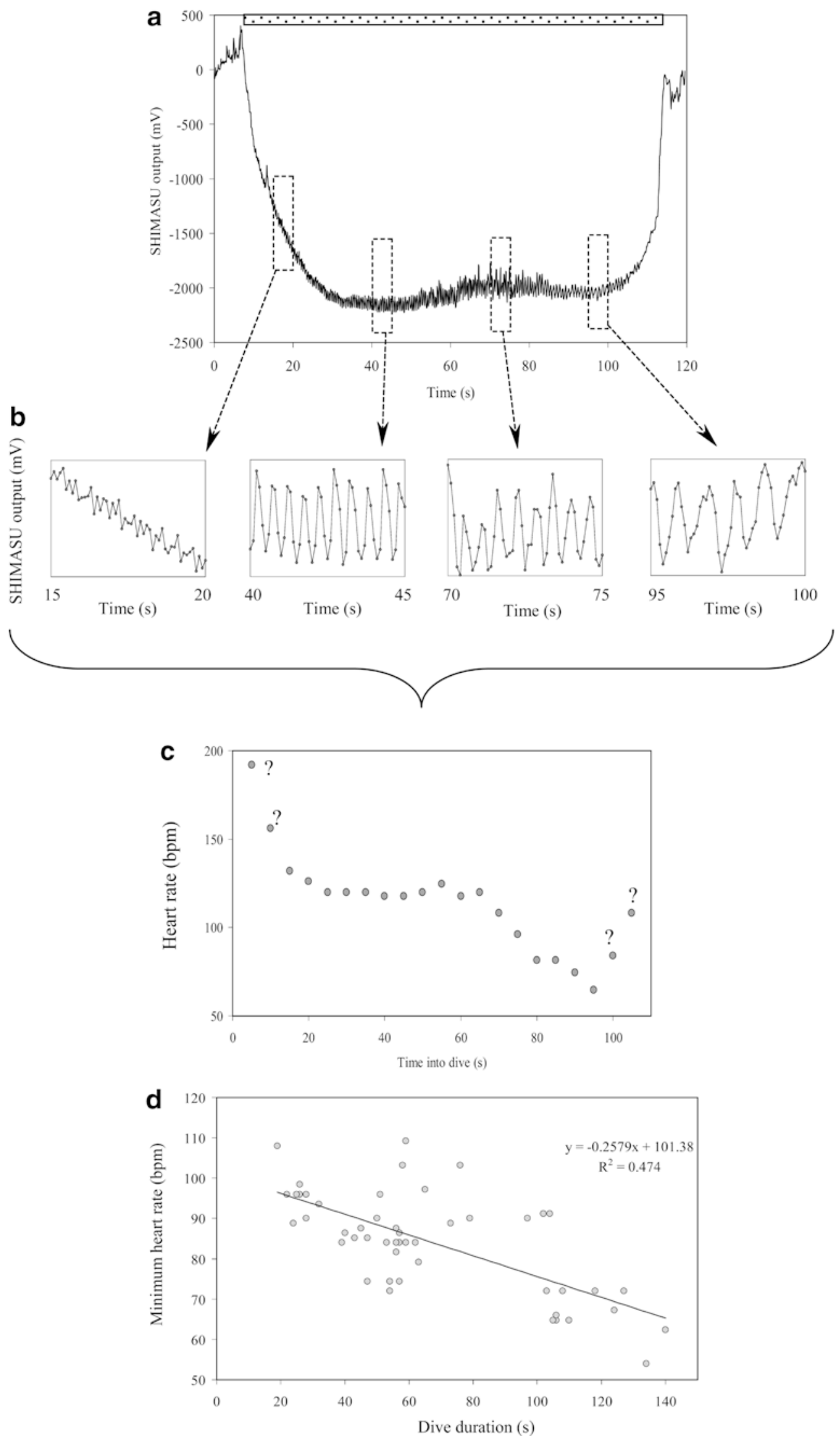
tion for the system. Although this configuration may be able to give some measure of the amount of faeces voided at each defecation event, we are unable to test this. Clearly, some configurations (Fig. 1) are inappropriate. Based on work to determine prey masses ingested with a Hall sensor/magnet system on the beak, we speculate that our proposed configuration 4 (Fig. 1) should give an output signal at defecation with which one, or more, of three measures could be used to assess guano quantity: (1) the maximum extent of the drop in signal strength, (2) the length of time of the drop in signal strength, or (3) the integral of the signal strength (cf. Wilson et al. 2002a). Should this fail, simple recognition of defecation events and a standard measure for the amount voided (cf. Fig. 3) could be used to calculate defecation rates and masses. This could be further refined by cognisance of the relationship between the guano mass voided and the interval between defecation events (Fig. 3).

The SHIMASU used on free-living penguins at sea recorded defecation events that concurred with general expectations. At the time of going to sea defecation rates are low, since most material ingested on the previous foraging trip has been ingested or given to the brood (Wilson et al. 1989; Peters 1997). After an initial time at sea, during which the birds feed (Wilson and Wilson 1990), defecation rates rise substantially as ingested material passes through the digestive tract (Fig. 6). Although we have no means of determining amounts voided yet, we note that defecation rates of ca. 10 events $\mathrm{h}^{-1}$ (once every $6 \mathrm{~min}$ ) approach those of the birds in captivity immediately after being fed (Fig. 3b). Rates of defecation in relation to those of ingestion will be a fascinating topic for the future to examine the extent to which free-living animals might regulate digestion according to circumstance (cf. Peters 1997; Gauthier-Clerc et al. 2000).

\section{Patterns of breathing}

We were able to monitor breathing in both captive and free-living penguins using the SHIMASU on land. Our success in doing this at sea was, however, limited. Although ventilation rates have been studied extensively in captivity (e.g. Butler and Woakes 1979), few researchers have succeeded in working with free-living animals, a notable exception being Le Boeuf et al. (2000). The development of a beak movement sensor, which records patterns of respiration in free-living penguins (Wilson et al. 2003) enabled us to confirm that the clear rhymicity that we observed in cloacal movement could be ascribed to breathing (Fig. 7a). We noted, in addition, that this rhymicity was apparent, even when the beak angle sensor was unable to document breathing (Fig. 7b); penguins only open and close their beaks during ventilation when air flux through the nares is inadequate to sustain metabolic rates (Wilson et al. 2003). Finally, closer examination of the patterns of ventilation as elucidated by the SHIMASU showed that the sensor output pattern per respiration followed a particular repetitive form (Fig. 8). We ascribe this movement in the cloacal region to the respiratory system of birds, which consists of numerous air sacs associated with the lungs (see Powell 2000, and references therein). The air sacs inflate and deflate in a complex, synchronised manner to optimise oxygen use (Kadono et al. 1963; Fedde et al. 1964; Powell 2000; Boggs et al. 2001). Although the sequence and timings of air-sac inflations during ventilation are not immediately obvious from our data, the sensitivity of the cloacal sensor to the internal pressures developed during ventilation make it a potentially useful tool in respiratory studies and may enable work of this ilk to be taken to the field.

Since metabolic activity in vertebrates requires oxygen, uptake of oxygen, mediated by ventilation rates, should help allude to energy expenditure. In this, it would be ideal to have information on both the rates of ventilation and the extent of tidal volume. Unfortunately, due to calibration problems mentioned earlier it is unlikely that the SHIMASU will be able to provide the latter, at least in the near future. Thus, considerations of metabolic rate using the SHIMASU must currently rely on being able to equate ventilation rates with ventilation volumes. We note here that numerous other factors will also play a critical role in the rate at which oxygen is taken up by the tissues, and this will have to be taken into consideration.

\section{Heart rate}

The measurement of heart rate is considered a particularly important method for the assessment of instantaneous energy expenditure by homeotherms (Owen 1969; Butler and Woakes 1979; Butler 1993). However, current methods for determining heart rate in free-living birds involve either implantation (e.g. Bevan et al. 1995) or sub-dermal sensors (e.g. Culik et al. 1989; Regel 1997). In addition, to circumvent some of the discomfort likely associated with this, some studies on birds have used heart rate sensors adapted for humans (Storch et al. 1999; Weimerskirch 2000, 2002), although such sensors do not work underwater. The SHIMASU technology appears to be a third option that will allow heart rate to be assessed relatively easily for a variety of activities, including diving. In this we note that our data conform to those of Green et al. (2003) in showing reduced heart rate over the course of dives (Fig. 9c) and a general tendency for minimum heart rate to decrease with dives of increasing duration (Fig. 9d). Our data from freeliving Magellanic penguins at sea do not show heart rate at the surface between dives unless the pauses are extensive (cf. Figs. 7c, 9b). This is almost certainly due to the frequency of measurement of data, because recording frequencies that approach the frequencies of the events to be measured do not give the temporal resolution necessary to define those events. RopertCoudert and Wilson (2003) suggest that for the effective 
measurement of events such as heart rate, a recording frequency of ca. ten times that the length of the event should be used. Since penguins during normal diving undergo substantial tachycardia at the surface (Green et al. 2003), a measurement frequency on the order of $40 \mathrm{~Hz}$ would be needed for birds at the surface, although $15 \mathrm{~Hz}$ would suffice for penguins underwater (Kooyman and Ponganis 1994; Green et al. 2003).

\section{Conclusions}

The system presented here for measurement of defecation, ventilation and heart rates is not perfect, and details should be worked out as to the best configuration and recording frequency for logging particular types of events according to the research focus and species being studied. The main difficulty stems from the elasticity of the tissue making up the cloaca, although it is this very elasticity that makes the cloaca such an interesting tympanum for responding to internal movements. Indeed, the Hall sensor/magnet system is extremely effective for assessing minute movements, and this feature may be used to allude to a variety of internal mechanical issues, such as gastric churning and heart rate, without the necessity of operative trauma. We consider that the SHIMASU can help count events well (breathing frequency, heart rate and frequency of defecation); however, difficulties in calibration (cf. Wilson et al. 2002a) make quantification of the extent of particular movements problematic. Despite these misgivings, we believe that future work with the SHIMASU may prove to be a valuable contribution to the study of energy use and flow in larger free-living animals and that the system should now be refined so that it can be used optimally and routinely.

Acknowledgements This work was funded by the ICSU and the Deutsche Forschungsgemeinschaft. Permission to carry out the work was granted by the Consejo Agrario de Santa Cruz and the Centro Patagonico, Chubut, both in Argentina. We are particularly grateful to Silvina S. for her constant support during this work, to Hagenbek's Tierpark for allowing us to work with their Humboldt penguins and to Vaccuumschmelze $\mathrm{GmbH}$ for help, as always, with the magnets.

\section{References}

Ancel A, Horning M, Kooyman GL (1997) Prey ingestion revealed by oesophagus and stomach temperature recordings in cormorants. J Exp Biol 200:149-154

Bannasch R, Wilson RP, Culik B (1994) Hydrodynamic aspects of design and attachment of a back-mounted device in penguins. J Exp Biol 194:83-96

Bevan RM, Woakes AJ, Butler PJ, Croxall JP (1995) Heart rate and oxygen consumption of exercising gentoo penguins. Physiol Zool 68:855-877

Boggs DF, Baudinette RV, Frappell PB, Butler PJ (2001) The influence of locomotion on air-sac pressures in little penguins. J Exp Biol 204:3581-3586
Butler PJ (1993) To what extent can heart rate be used as an indicator of metabolic rate in free-living marine mammals. Symp Zool Soc Lond 66:317-332

Butler PJ, Woakes AJ (1979) Changes in heart rate and respiratory frequency during natural behaviour of ducks, with particular reference to diving. J Exp Biol 108:419-428

Charrassin J-B, Kato A, Handrich Y, Sato K, Naito Y, Ancel A, Bost C-A, Gauthier-Clerc M, Ropert-Coudert Y, Le Maho Y (2001) Feeding behavior of free-ranging penguins determined by oesophageal temperature. Proc R Soc Lond B Biol Sci 268:151-157

Cholewicki J, Panjabi MM, Nibu K, Macias ME (1997) Spinal ligament transducer based on a Hall effect sensor. J Biomech 30:291-293

Coates DB, Penning P (2000) Measuring animal performance. In: 't Mannetje L, Jones RM (eds) Field and laboratory methods for grassland and animal production research. CABI, Oxford, UK, pp 353-402

Cobern V, Peterson JR, Otis AB (1983) A Hall effect transducer for measuring length changes in mammalian diaphragm. J Appl Physiol 55:635-641

Culik B, Adelung D, Heise M, Wilson RP, Spairani HJ, Coria NR (1989) In situ heart rates of incubating Adelie penguins. Polar Biol 9:365-370

Culik B, Wilson RP, Bannasch R (1994) Underwater swimming at low energetic cost y by pygoscelid penguins. J Exp Biol 197:6578

Elton CS (1927) Animal ecology. McMillan, New York

Fedde MR, Burger RE, Kitchell RL (1964) Electromyographic studies of the effects of bilateral, cervical vagotomy on the action of the respiratory muscles of the domestic duck. Poult Sci 43:1177-1184

Gales R, Renouf D (1993) Detecting and measuring food and water intake in captive seals using temperature telemetry. J Wildl Manag 57:514-519

Gauthier-Clerc M, Le Maho Y, Clerquin Y, Drault S, Handrich Y (2000) Penguin fathers preserve food for their chicks. Nature 408:928-929

Green JA, Butler PJ, Woakes AJ, Boyd IL (2003) Energetics of diving in macaroni penguins. J Exp Biol 206:43-57

Hall EH (1879) On a new action of the magnet on electric currents Am J Math 2:287-289

Jackson S (1992) Do seabird gut sizes and mean retention times reflect adaptations to diet and foraging method. Physiol Zool 65:674-697

Kadono H, Okada T, Ono K (1963) Electromyographic studies on the respiratory muscles of the chicken. Poult Sci 42:121128

Kooyman GL, Ponganis PJ (1994) Emperor penguin oxygen consumption, heart rate and plasma lactate levels during graded swimming exercises. J Exp Biol 195:199-209

Krysl LJ, Galyean ML, Estell RE, Sowell BF (1988) Estimating digestibility and faecal output in lamb using internal and external markers. J Agricult Sci Camb 111:19-25

Lawson JW, Miller EH, Noseworthy E (1997) Variation in assimilation efficiency and digestive efficiency of captive harp seals (Phoca groenlandica) on different diets. Can J Zool 75:1285-1291

Le Boeuf BJ, Crocker DE, Grayson J, Gedamke J, Webb PM, Blackwell SB, Costa D (2000) Respiration and heart rate at the surface between dives in northern elephant seals. J Exp Biol 203:3265-3274

Owen RBJ (1969) Heart rate, a measure of metabolism in bluewinged teal. Comp Biochem Physiol A 31:431-436

Peters G (1997) Die Regulation der Verdauungsprozesse bei Pinguinen (Spheniscidae). PhD thesis, Universität Kiel, Kiel, Germany

Plötz J, Bornemann H, Knust R, Schröder A, Bester M (2001) Foraging behaviour of Weddell seals, and its ecological implications. Polar Biol 24:901-909

Powell FL (2000) Respiration. In: Whittow GC (ed) Avian physiology, 5th edn. Academic, San Diego, pp 233-264 
Regel J (1997) Auswirkungen von Störreizen auf das Verhalten, die Magentemperatur und die Herzschlagrate bei Pinguinen. PhD thesis, Universität Kiel, Kiel, Germany

Ropert-Coudert Y, Wilson RP (2003) Subjectivity in bio-logging science: do logged data mislead? Mem Natl Inst Polar Res (Tokyo) (in press)

Rosen DAS, Trites AW (2000) Digestive efficiency and dry-matter digestibility in Steller sea lions fed herring, pollack, squid, and salmon. Can J Zool 78:234-239

Simeone A, Wilson RP (2003) In depth studies of Magellanic foraging behaviour: can we estimate prey consumption by perturbations in the profile? Mar Biol (in press)

Storch S, Grémillet D, Culik BM (1999) The telltale heart: a noninvasive method to determine the energy expenditure of incubating great cormorants Phalacrocorax carbo carbo. Ardea $87: 207-215$

Taylor SS, Boness DJ, Majluf P (2001) Foraging trip duration increases for Humboldt penguins tagged with recording devices. J Avian Biol 32:369-372

Weimerskirch H, Guionnet T, Martin J, Shaffer SA, Costa DP (2000) Fast and fuel-efficient? Optimal use of wind by flying albatrosses. Proc R Soc Lond 267:1869-1874

Weimerskirch H, Shaffer SA, Mabille G, Martin J, Boutard O, Rouanet JL (2002) Heart rate and energy expenditure of incubating wandering albatrosses: basal levels, natural variation, and the effects of human disturbance. J Exp Biol 205:475-483

Williams TD (1995) The penguins. Oxford University Press, Oxford, UK

Wilson RP (2003) Penguins predict performance. Mar Ecol Prog Ser 249:305-310

Wilson RP, Culik BM (1992) Packages on penguins and deviceinduced data. In: Priede IM, Swift SM (eds) Wildlife telemetry: remote monitoring and tracking of animals. Ellis Horward, Chichester, UK, pp 573-580
Wilson RP, Liebsch N (2003) Up-beat motion in swinging limbs: new insights into assessing movement of free-living marine vertebrates. Mar Biol 142:537-547

Wilson RP, Wilson M-P (1990) Foraging ecology of breeding Spheniscus penguins. In: Davies LS, Darby J (eds) Penguin biology. Academic, San Diego, pp 181-206

Wilson RP, Ryan PG, Wilson M-P (1989) Sharing food in the stomachs of seabirds between adults and chicks; a case for delayed gastric emptying. J Comp Biochem Physiol A 94:461-466

Wilson RP, Cooper J, Plötz J (1992) Can we determine when marine endotherms feed: a case study with seabirds. J Exp Biol 167:267-275

Wilson RP, Pütz K, Charrassin J-B, Lage J (1995) Artifacts arising from sampling interval in dive depth studies of marine endotherms. Polar Biol 15:575-581

Wilson RP, Pütz K, Peters G, Culik B, Scolaro JA, Charrassin J-B, Ropert-Coudert Y (1997) Long term attachment of transmitting and recording devices to penguins and other seabirds. Wildl Soc Bull 25:101-106

Wilson RP, Steinfurth A, Ropert-Coudert Y, Kato A, Kurita M (2002a) Lip-reading in remote subjects: an attempt to quantify and separate ingestion, breathing and vocalisation in free-living animals. Mar Biol 140:17-27

Wilson RP, Ropert-Coudert Y, Akiko K (2002b) Rush and grab strategies in foraging marine endotherms: the case for haste in penguins. Anim Behav 63:85-95

Wilson RP, Simeone A, Luna-Jorquera G, Steinfurth A, Jackson S, Fahlman A (2003) Patterns of respiration in diving penguins: Is the last gasp based on an inspired tactic? J Exp Biol 206:17511763

Winship AJ, Trites AW (2002) Prey consumption of Steller sea lions (Eumetopias jubatus) off Alaska: how much prey do they require? Fish Bull (Wash DC) 101:147-167 